\title{
POBREZA E DESENVOLVIMENTO COMO PARADOXOS DA SUSTENTABILIDADE: REFLEXÕES SOBRE A INTERVENÇÃO HUMANA NO MEIO AMBIENTE
}

\author{
POVERTY AND DEVELOPMENT AS PARADOXES OF SUSTAINABILITY: \\ REFLECTIONS ON THE HUMAN INTERVENTION IN THE ENVIRONMENT
}

\author{
Amadeu Elves Miguel ${ }^{1}$ \\ Guilherme Nazareno Flores ${ }^{2}$ \\ Ricardo Stanziola Vieira ${ }^{3}$
}

\section{RESUMO}

$\mathrm{O}$ artigo busca abordar a pobreza e o desenvolvimento enquanto paradoxos da sustentabilidade, refletindo sobre a intervenção humana no meio ambiente e partindo do pressuposto de que o ecossistema em que vivemos se transforma devido a ação direta do ser humano sobre ele tanto pelo desenvolvimento como pela pobreza. Também busca mostrar que a intensidade desta intervenção é de tal forma que muitas vezes a destruição de recursos naturais ultrapassa a própria capacidade de recuperação dos ecossistemas. Para a materialização desta pesquisa foi usado o Método Dedutivo e as técnicas do referente, das categorias básicas e dos conceitos operacionais, sendo que, para se alcançar o objetivo proposto, o trabalho encontra-se desdobrado da seguinte forma: 1. Introdução; 2. O Desenvolvimento Industrial e a Emergência do Desenvolvimento Sustentável; 3. Desenvolvimento Humano e Desenvolvimento Sustentável; 4. Pobreza e (in)Justiça Ambiental: $o$ Caso Summers; 5. Pobreza e Degradação Ambiental e 6. Considerações Finais.

Palavras-chave: Pobreza. Desenvolvimento. Desenvolvimento Sustentável e Meio Ambiente.

\begin{abstract}
This article presents that aims to make an approach around poverty and development as paradoxes of sustainability, reflecting on human intervention in the environment. The study assumes that the ecosystem in which we live is constantly vary and become due to the direct action of man on it by both the development as poverty and that the intensity of this intervention is such that often the destruction natural resources surpasses the resilience of ecosystems. To materialize this research was used Deductive Method and techniques of the referent, the basic categories and operational concepts, and to achieve the proposed objective, the work is broken down as follows: 1. Introduction 2. The Industrial Development and the

\footnotetext{
1 Mestrando no Programa de Pós-Graduação Stricto Sensu em Ciência Jurídica - PPCJ/UNIVALI (SC). Docente dos Cursos de Licenciatura em Direito do Instituto Superior de Gestão, Comércio e Finanças - ISGECOF - Moçambique. Docente dos Cursos de Direito da Escola Superior de Economia e Gestão ESEG - Moçambique. Email: amadeumiguel1@hotmail.com

2 Doutorando e mestre em Direito pela Universidade do Vale do Itajaí - UNIVALI/SC. Professor Universitário e Servidor Público. Email: guilhermeflores. adv@gmail.com

3 Pós-Doutor pelo Centro de Pesquisa Interdisciplinar em Direito Ambiental, Urbanismo e gestão do território Crideau - Universidade de Limoges - França. Docente Titular nos Cursos de Mestrado e Doutorado em Ciência Jurídica e no Curso de Mestrado em Políticas Públicas - UNIVALI. Email: ricardostanziola@ univali.br
} 
Emergence of Sustainable Development 3. Human Development and Sustainable Development 4. Poverty and (in) Environmental Justice: Case Summers 5. Poverty and Environmental Degradation and 6. Final.

Keywords: Poverty. Development. Sustainable Development and Environment.

\section{Introdução}

O meio ambiente - ou ecossistema - em que vivemos está em constante transformação devido à intervenção humana sobre ele, que trouxe e continua a trazer consequências graves que se tornam evidentes em diferentes escalas. A intensidade desta intervenção, o uso contínuo e crescente dos recursos não renováveis são tais que, muitas vezes, a destruição de recursos ultrapassa a própria capacidade de recuperação dos ecossistemas e não permite que a natureza se renove. Isto parece ser uma das características mais flagrantes da atualidade.

O Desenvolvimento Industrial (século XVIII) trouxe mais ameaças do que se esperava para o meio ambiente. A utilização generalizada do meio ambiente para sustentar o padrão de vida moderno propiciou à humanidade testemunhar a má qualidade do ar, da água, a destruição de florestas e a extinção de várias espécies de animais, além do buraco da camada de ozônio, o efeito estufa, dentre outras questões.

A partir dos anos 1970 com o avanço da ciência, as desvantagens da industrialização passaram a ser mais visíveis por conta do empobrecimento da biodiversidade, de poluição e alterações climáticas, explosão demográfica nos grandes centros urbanos, escassez de recursos naturais, incapacidade de reuso de resíduos, contaminação das águas dos rios e dos oceanos.

O modelo de desenvolvimento baseado no consumo excessivo de recursos naturais levou a um desastre energético acima do suportável pelo planeta, causando um enorme cenário de poluição do ar e da água, ameaças à natureza, destruição da camada de ozônio, aquecimento global, dentre outros, o que mais tarde Hobsbawn denominou de era dos extremos ${ }^{4}$.

${ }^{4} \mathrm{O}$ Autor referia-se à época mais extraordinária da humanidade, caraterizada por grandes avanços de ordem científica, tecnológica, conquistas materiais, econômicas e sociais, ao mesmo tempo em que ocorriam calamidades de grandes dimensões, pandemias alarmantes, destruição e insustentabilidade global e problemas que transcendem a agendas domésticas dos Estados. In HOBSBAWN, Eric. Globalização, Democracia e Terrorismo. Trad. José Viegas. São Paulo: Companhia das Letras, 2007, p.9.
Neste contexto, a hipótese suscitada constitui-se na adoção de um conceito de Justiça Ambiental como protagonista de sustentabilidade. A hipótese que se vislumbra é verificar como o conceito de Desenvolvimento pode se adequar aos princípios sustentáveis para pôr termo à degradação ambiental e à pobreza, bem como verificar se a pobreza é causa ou consequência de degradação ambiental.

Por fim, o objetivo deste artigo é abordar como o modelo de desenvolvimento tem sido um gerador de pobreza e de injustiça ambiental, circunstâncias do mundo moderno que contribuem com o direcionamento da humanidade à contramão da sustentabilidade global.

\section{Da relação humana com o ambiente ao liberalismo econômico: reflexos ao meio ambiente}

As relações sociais são movimentos cíclicos que se alteram constantemente de acordo com diversas circunstâncias, sendo necessário um esforço para compreender os contextos em que elas ocorrem.

Nessas relações, desde os tempos mais remotos, o comportamento humano e a natureza mantêm-se em conflito. Na Antiguidade, sua postura em relação à natureza era exclusivamente antropocêntrica ${ }^{5}$, em que o meio ambiente servia inteiramente aos seus desejos $^{6}$. Neste conflito de interesses, a dicotômica convivência entre ser humano versus natureza, integração versus exploração, a ideia da acumulação de

\footnotetext{
5 "A visão kantiana do mundo fundou-se no antropocentrismo, cuja teoria apregoa que os objetos são contaminados pela razão humana, criando a ideia de que o ser humano é dono do meio em que vive e ETA acima dos recursos naturais, criando indivíduos como um fim em si mesmos, indiferentes à vontade coletiva e do meio ambiente circundante". (GORCZEVSKI, Clóvis e MORAIS, Danusa Espíndola. A crise da percepção ambiental e os mecanismos constitucionais que permitem o exercício da cidadania na proteção do meio ambiente: Uma análise a partir da obra A Teia da Vida, de Fritjof Capra e A Teoria da Constituição como Ciência da Cultura, de Peter Haberle. In: CUSTÓDIO; André Viana. BALDO, Iumar Junior (orgs).Meio Ambiente Constituição \& Políticas Públicas. Curitiba: Multideia, 2011, p.61).

${ }^{6}$ SOARES, Remi Aparecida de Araújo. Proteção ambiental e desenvolvimento econômico. $1^{\text {a }}$ Ed., Curitiba. Juruá, 2005, p 22.
} 
capital aos poucos vai minando o pensamento social, tornando-se uma verdade absoluta e um objetivo perseguido por muitos.

Assim, num salto pela linha do tempo, é de se reservar aos séculos que testemunharam as revoluções industriais ${ }^{7}$ a história deste desenvolvimento e da relação do ser humano com o meio ambiente, eis que é deste momento histórico que o nascimento de cidades, na maioria das vezes de forma desordenada ${ }^{8}$, tem uma maior influência no modo de vida, cultura, atitudes que vivemos hoje. No entender de Ferrer:

[...] todas las civilizaciones han desarrollado medios, más o menos eficaces, más o menos agresivos, para poner a sus entorno natural al servicio de sus objetivos colectivos o individuales. Estas intervenciones han supuesto en ocasiones el deterioro o desaparición de ecosistemas más allá de lo que convenía a las mismas colectividades que las acometían, produciéndose la consciencia de que, en su proceso de poner la naturaleza a su servicio, comprometían la capacidad de ésta de proveer aquellos recursos que necesitaban?.

\footnotetext{
${ }^{7}$ Segundo Anselmo Lázaro Branco houve três Revoluções Industriais, tendo a primeira "iniciado na Inglaterra, (...) na metade do século 18, que teve como um dos principais acontecimentos a invenção da máquina a vapor e sua aplicação na produção têxtil (...) aumentou a quantidade de profissões, de mercadorias produzidas, de unidades de produção (as fábricas); as cidades passaram a crescer, em alguns casos, num ritmo bastante acelerado; o campo conheceu um processo de mecanização; foram estruturadas ferrovias, que aumentaram a capacidade de circulação de mercadorias e pessoas, além de terem agilizado o transporte; a necessidade por matériasprimas agrícolas e minerais ampliou-se significativamente". A "segunda Revolução Industrial, entre meados do século 19 e meados do século 20, diversos inventos passaram a ser produzidos e comercializados: automóvel, telefone, televisor, rádio, avião." E, logo após a Segunda Grande Guerra, a economia internacional começou a passar por profundas transformações. Elas caracterizam a Terceira Revolução Industrial, diferenciando-a das duas anteriores, uma vez que engloba mudanças que vão muito além das transformações industriais. Essa nova fase apresenta processos tecnológicos decorrentes de uma integração física entre ciência e produção, também chamada de Revolução Tecnocientífica. (Disponível em: <http://educacao. uol.com.br/geografia/revolucoes-industriais-primeira-segunda-e-terceirarevolucoes.jhtm>. Acesso em 16.11.2011)

${ }^{8} \mathrm{O}$ êxodo rural, a descoberta das máquinas a vapor, a qualificação da mão de obra, as relações comerciais e trabalhistas promoveram "a sedimentação de uma sociedade socioambientalmente deformada, não só do ponto de vista estrutural, mas também da cultura, da educação, da racionalidade críticoreflexiva, contém determinantes que não podem ser resumidos unicamente a um problema político-organizacional. A exclusão e a desordem social possuem razões muito mais amplas do que puramente uma negligência nas formas de administrar a política pública de saneamento, a habitação popular, os planos gestores, desafetação das áreas verdes etc." (BALDO, Iumar Junior. CUSTÓDIO, André Viana. Desenvolvimento Urbano: Um discurso sobre a organização socioambiental e habitacional so a panorâmica da igualdade e da justiça em John Rawls. In: CUSTÓDIO; André Viana; BALDO, Iumar Junior (orgs). Meio Ambiente Constituição \& Políticas Públicas.. Curitiba: Multideia, 2011, pag.17)
}

${ }^{9}$ FERRER, Gabriel Real. La construcción del Derecho Ambiental.Revista Arazandi de Derecho Ambiental. Pamplona. España. n. 1, 2002. P. 73.
Nesse sentido, o período de revoluções atribuiu ao mundo um novo rumo, em que a industrialização e o capital tomaram as rédeas do sistema, passando a ditar as regras e trazendo à tona uma infinidade de problemas socioambientais decorrentes deste desenvolvimento.

O impacto da ação humana sobre o meio ambiente, para Chiras, depende de variáveis históricas, como o modo de produção, a estrutura de classes, os recursos tecnológicos e a cultura de cada sociedade ao longo do tempo. A Revolução Industrial estabelece a necessidade social da expansão permanente do mercado, como forma de garantir a acumulação de capital que realimenta a economia capitalista. Os recursos naturais não renováveis - minérios, combustíveis fósseis, por exemplo - passaram a ser consumidos mais aceleradamente a partir desta época. Fauna e flora passam a ser ameaçadas e recursos como água, solo e ar tornam-se alvos de poluição térmica, visual, sonora, radioativa. A concepção de crescimento ilimitado é gerada neste contexto histórico, influenciando países de diferentes orientações políticas e ideológicas ${ }^{10}$. Assim, a partir desta construção se pode perceber um contexto no qual o capital passou a imperar pela necessidade de sua acumulação, o que se constitui no ideário capitalista.

Por essa perspectiva de mundo, o ser humano, ao longo da evolução socioeconômica, explorou, interferiu e modificou drasticamente o meio ambiente ${ }^{11}$. Por consequência, dada a acentuada degradação presenciada até então, esse incremento vertiginoso na forma de exploração de recursos naturais passa a ameaçar aquele que se via como senhor e proprietário dos bens ambientais. Nestes termos, vale dizer:

(...) a utilização ilimitada dos recursos naturais revelou-se irracional, pela tamanha degradação, pois o homem não pode ser visto como ser supremo e isolado do meio, eis que representa um todo maior,

\footnotetext{
${ }^{10}$ CHIRAS, D.D. New Visions of Life: Evolution of a Living Planet. I: Environmental Science: Action for a Sustainable Future. $3^{\circ}$ Edition. Benjamim Cummings Publishing. Cap: 02. Disponível em: $<$ http://xucurus. blogspot.com/2010/08/meio-ambiente-e-producao-de-lixo.html>. Acesso em 16.11.2011.

11 GORCZEVSKI, Clóvis e MORAIS, Danusa Espíndola. A crise da percepção ambiental e os mecanismos constitucionais que permitem o exercício da cidadania na proteção do meio ambiente: Uma análise a partir da obra A Teia da Vida, de Fritjof Capra e A Teoria da Constituição como Ciência da Cultura, de Peter Haberle. In: CUSTÓDIO; André Viana. BALDO, Iumar Junior (orgs). Meio Ambiente Constituição \& Políticas Públicas. Curitiba: Multideia, 2011, p.62
} 
ou seja, como refere Capra, a vida é composta por 'sistemas vivos', em que o homem é apenas uma parte desse sistema, e por sua condição racional possui capacidade de organização política, tecnológica, científica e econômica, sem necessidade de desligar-se do ecossistema vivo do qual faz parte. ${ }^{12}$

O ser humano é parte do meio em que vive, não podendo dissociar-se dele; contudo, é notável que o desenvolvimento do processo de industrialização e da era tecnológica, este não demorou a contaminar o ambiente em que vive, como se dele não fizesse parte. Tal fenômeno talvez ocorra pela falta de percepção de sua posição no planeta e da noção de que os bens ambientais não são finitos.

A atividade humana - diga-se negligente - à busca pelo lucro gera pobreza e riqueza, formando uma sociedade dividida em dois extremos, mas que convivem lado a lado nos mesmos conglomerados urbanos, contaminando as águas, o ar que consomem, o solo do qual retiram seus alimentos, dentre outros.

Redundante dizer que este cenário de exploração econômica de recursos naturais se constitui no mais significativo ponto demarcatório a partir da era industrial, ou seja, da implantação definitiva do que se convencionou chamar capitalismo industrial ${ }^{13}$. Mais adiante, a pós-modernidade desponta, na era da velocidade, com uma forte descrença no poder absoluto da razão, com desprestígio ao Estado, em sua forma tradicional. Internacionalmente, decai a noção tradicional de soberania, pois as fronteiras perdem resistência em favor da constituição de expressivos blocos políticos e econômicos, intensificação e circulação de capitais $^{14}$. O fenômeno da globalização surge com o século XXI, evidenciando a desigual-

\footnotetext{
${ }^{12}$ GORCZEVSKI, Clóvis e MORAIS, Danusa Espíndola. A crise da percepção ambiental e os mecanismos constitucionais que permitem o exercício da cidadania na proteção do meio ambiente: Uma análise a partir da obra A Teia da Vida, de Fritjof Capra e A Teoria da Constituição como Ciência da Cultura, de Peter Haberle. In: CUSTÓDIO; André Viana. BALDO, Iumar Junior (orgs). Meio Ambiente Constituição \& Políticas Públicas. Curitiba: Multideia, 2011, p.62

${ }^{13}$ BREITENBACH, Camila e REIS, Jorge Renato.(In)suficiência dos preceitos constitucionais ambientais na pós-modernidade frente ao paradigma econômico. In: CUSTÓDIO; André Viana. BALDO, Iumar Junior (orgs). Meio Ambiente Constituição \& Políticas Públicas. Curitiba: Multideia, 2011, p. 73.

${ }^{14}$ PEREIRA, Jane Reis Gonçalves. Apontamentos sobre a aplicação das normas de direito fundamental nas Relações Jurídicas entre Particulares. In: BARROSO, Luis Roberto. A nova Interpretação constitucional: Ponderação, Direitos fundamentais e Relações Privadas. Rio de Janeiro: Renovar, 2003, p. 149.
}

dade das relações; além disso, presencia-se grande avanço da ciência e da tecnologia ${ }^{15}$.

Nesta seara, Giddens alerta que todo o contexto apresentado anteriormente está embasado no fenômeno da transnacionalização ${ }^{16}$ presente no novo contexto mundial, surgido principalmente a partir da intensificação das operações de natureza econômico-comercial no período do pós-Guerra Fria, caracterizado, especialmente, pela desterritorialização, expansão capitalista, enfraquecimento da soberania e emergência de ordenamentos jurídicos gerados à margem do monopólio estatal ${ }^{17}$.

A pós-modernidade deflagrou uma mudança no mundo. Se não uma mudança geográfica, ao menos uma nova forma nas relações desenvolvidas entre pessoas e estados e, principalmente, no modelo adotado em que vigora a mundialização da economia, a globalização, a queda de fronteiras, baseada em políticas neoliberais.

Assim, a expansão capitalista acabou por enfraquecer, por mitigar a soberania dos Estados e possibilitando uma queda de fronteiras, em que tudo pode circular mais livremente fortalecendo o capital, fazendo o mundo caminhar no sentido da consolidação deste. Para Cruz e Bodnar,

\footnotetext{
${ }^{15}$ BREITENBACH, Camila e REIS, Jorge Renato.(In)suficiência dos preceitos constitucionais ambientais na pós-modernidade frente ao paradigma econômico. In: CUSTÓDIO; André Viana. BALDO, Iumar Junior (orgs). Meio Ambiente Constituição \& Políticas Públicas. Curitiba: Multideia, 2011, p. 70.

${ }^{16}$ A transnacionalidade insere-se no contexto da globalização e liga-se fortemente à concepção do transpasse estatal. Enquanto globalização remete à ideia de conjunto, de globo, enfim, o mundo sintetizado como único; transnacionalização está atada à referência do Estado permeável, mas tem na figura estatal a referência do ente em declínio. Com efeito, não se trata mais do Estado-territorial, referência elementar surgida após a Paz de Vestfália e que se consolida até o século XX, viabilizando a emergência do Direito Internacional sob amparo da ideia soberana. Esse é um quadro alterado que se transfigura de internacional (inter-nações) para transnacional (transnações), de soberania absoluta para soberania relativa, de relações territoriais para relações virtuais, de trânsito entre fronteiras para trânsito em espaço único. A desterritorialização (por exemplo, quando a produção de um bem ocorre em vários países) é uma das principais circunstâncias que molda o cenário transnacional, especialmente porque diz respeito ao aspecto além da fronteira, pois não é o espaço estatal e também não é o que liga dois ou mais espaços estatais. O território transnacional não é nem um nem outro e é um e outro, posto que se situa na fronteira transpassada, na borda permeável do Estado. Com isso, por ser fugidia, borda também não é, pois fronteira delimita e a permeabilidade traz consigo apenas o imaginário, o limite virtual. In: Transnacionalização: o emergente cenário do comércio mundial. Revista portuária Economia \& Negócios. Disponível em: <http://www. revistaportuaria.com.br/site $/$ home $=$ artigos $\& n=C C N U \& t=$ transnacionaliz aco-emergente-cenario-comercio-mundial>. Acesso em 20.07.2013

17 GIDDENS, Antony. As consequências da modernidade. Tradução de Raul Fiker. Sao Paulo. Unesp. 1991, p.72. In CRUZ, Paulo Marcio, BODNAR, Zenildo, STAFFEN, Marcio Ricardo. Transnacionalización, Sostenibilidad y el nuevo paradigma del Derecho in Siglo XXI. Revista Opinión Jurídica Universidad de Medellín, 2011. p. 13.
} 
o cenário transnacional da atualidade pode ser caracterizado como uma complexa teia de relações políticas, sociais, econômicas e jurídicas, no qual emergem novos atores, interesses e conflitos, os quais demandam respostas eficazes do direito. Estas respostas dependem de um novo paradigma do direito que melhor oriente e harmonize as diversas dimensões implicadas ${ }^{18}$.

Esta transnacionalização, somada ao fenômeno da globalização econômica, pode ser entendida como uma internacionalização da economia, na qual se pode destacar a forma instantânea com que se alastra uma informação, as diversas possibilidades para a imediata comunicação, a conexão de mercados e de economias de países e blocos econômicos. A globalização propiciou à humanidade um imenso desenvolvimento tecnológico, até então "hollywoodiano"; hoje é tomado como uma panaceia adotada pela civilização para justificar o uso, consumo e a criação de bens de consumo e, assim, proporcionar bem-estar ao ser humano.

Some-se a isto o fato de que a ideia precípua trazida pela categoria globalização era a de que, nas indústrias, as novas tecnologias, por si só, seriam responsáveis pelo aumento da produtividade e pela obsolescência da mão de obra humana, o lucro, a redução das desigualdades. Não é necessário dizer que o que se viu foi o aumento da desigualdade social, em que uma porcentagem gigantesca do capital estava nas mãos de uma ínfima minoria de pessoas e o restante deveria ser dividido pelos demais, ocasionando miséria, desemprego, desigualdade social e, obviamente, degradação ambiental.

Assim, a atividade econômica decorrente da industrialização acaba por provocar imensas e profundas alterações no meio em que estão geograficamente instaladas, seja desmatando, poluindo rios, contaminando solo. Na busca pelo lucro, as empresas precisam retirar da natureza a matéria prima para construírem seus produtos. Para tanto, precisarão de energia elétrica, custear funcionários, ter uma estrutura e então precisarão vender seus produtos, o que o farão por uma empresa de marketing e propaganda.

\footnotetext{
${ }^{18}$ CRUZ, Paulo Marcio, BODNAR, Zenildo.O novo paradigma do Direito na Pós Modernidade. Revista de Estudos Constitucionais, Hermenêutica e Teoria do Direito (RECHTD). UNISINOS 3(1): 75-83 janeiro-junho 2011. P.76.
}

Em pouco tempo, o produto, produzido em quantidade muito superior à demanda de mercado, estará nas residências de milhares e milhares de pessoas por meio de comerciais de rádio e televisão, mensagens eletrônicas, propagandas em sítios cibernéticos ou qualquer outro meio tecnológico disponível ${ }^{19}$.

Aquelas pessoas que trabalham para desenvolver um produto em uma empresa e que recebem salários por isto, são as mesmas que agora utilizarão seus vencimentos para a aquisição de outros bens de consumo produzidos por outras pessoas que também recebem salários e que também têm necessidades de consumo, seja alimentação, lazer, seja vestuário, serviços.

$\mathrm{O}$ consumo tem se revelado um dos grandes vilões do meio ambiente nos dias atuais em virtude da produção de resíduos ${ }^{20}$, a contribuição da rápida obsolescência de equipamentos ${ }^{21}$, dentre outros aspectos que agravam o problema da disposição final ambientalmente adequada. Para Ferreira:

o avanço tecnológico e as políticas econômicas vêm se expandindo cada vez mais, incentivando demasiadamente o consumo das sociedades, seja com uma melhora no designer de um produto já comercializado, ou no lançamento de uma nova versão, ou ainda, pelas facilidades das linhas de crédito espontâneas das empresas. $(\ldots)^{22}$.

E assim se desenvolve um ciclo em que as pessoas trabalham para consumir, fomentar a riqueza nas mãos de uns poucos, num sistema cruel e que muitas vezes não é percebido pelas pessoas que dele fazem parte.

\footnotetext{
19 Neste sentido esclarece Fernanda Furtado que "os bens e serviços a serem produzidos devem ser apenas aqueles necessários para a sociedade, o parâmetro não deve ser a rentabilidade, e a eficiência econômica deve ser medida pelo grau de afetação aos recursos naturais". In FURTADO, Fernanda Andrade Mattar. Concepções éticas da proteção ambiental. Brasília. Instituto Brasiliense de Direito Público, 2003, p, 152.

20 O lixo urbano é um dos maiores problemas ambientais da atualidade, pois pelos moldes de consumo adotado pela maioria das sociedades modernas provocam o aumento contíguo e exagerado das quantidades de lixo produzido. FERREIRA, Juliana Martins de Bessa e FERREIRA, Cláudio Antonio. A sociedade da informação e o desafio da sucata eletrônica. Revista de Ciências Exatas e Tecnologia. Faculdade Anhanguera, São Paulo. Vol. III, no. 3, ano 2008. p 160.

${ }^{21} \mathrm{O}$ lixo eletroeletrônico teve origem pela fixação do ser humano pelos avanços tecnológicos, pela lei da oferta e da procura, pela competitividade capitalista, pelo consumo elevado e o ritmo rápido de inovação tecnológica dos equipamentos eletrônicos, os quais se transformam em sucata numa velocidade assustadora. FERREIRA, Juliana Martins de Bessa e FERREIRA, Cláudio Antonio. A sociedade da informação e o desafio da sucata eletrônica. Revista de Ciências Exatas e Tecnologia. Faculdade Anhanguera, São Paulo. Vol. III, nº. 3, ano 2008. p 158.

${ }^{22}$ Idem, ibidem, p. 162.
} 
Como arremate, contrariando a lógica estabelecida e imposta pelo capitalismo, o que deveria prevalecer é uma ponderação entre a proteção ambiental e o desenvolvimento econômico, harmonizando-os e conciliando-os e, fazendo sempre preponderar o interesse coletivo por meio de um equilíbrio ecológico.

\section{Desenvolvimento sustentável e governan- ça socioambiental como categorias privile- giadas: rumo a um novo direito da sustenta- bilidade.}

Tal como a essência teórica do Direito Ambiental vem evoluindo do tecnicismo para o socioambientalismo, também as categorias de Desenvolvimento Sustentável e Governança Ambiental têm passado por importantes transformações. O conceito de Desenvolvimento Sustentável em si já é fruto de uma importante tomada de consciência axiológica mais complexa ${ }^{23}$ : como reatar com o crescimento de forma a fazer recuar as desigualdades e a pobreza, sem deteriorar o meio ambiente legado às futuras gerações? O conceito conheceu uma evolução sem precedentes, reconhecendo as três dimensões - econômica, ambiental e social - base do que seria posteriormente um incremento de participação da cidadania em um contexto globalizado.

$\mathrm{O}$ mesmo se pode dizer em relação à Governança Ambiental. Esta categoria recente que pareceria uma utopia há algumas décadas, atualmente constitui uma necessidade e vem dando o tom do discurso nacional (governança ambiental local) e internacional (governança ambiental global).

Isto fica claro sobretudo após a entrada em vigor de tratados como a Convenção da Diversidade Biológica, a Convenção Quadro das Nações Unidas sobre Mudança Climática e o Protocolo de Quioto. Ambos os conceitos discutidos têm levado a uma nova formatação de Governança e Políticas Públicas Ambientais ${ }^{24}$, que passam a ser marcadas por uma maior participação da sociedade civil nos processos decisórios e de gestão ambiental.

\footnotetext{
${ }^{23} \mathrm{Cf}$. BROWN, Lester R. Eco-économie - une autre croissance est possible, écologique et durable. Paris : Seuil, 2003.

${ }^{24}$ Cf. LEIS, Héctor Ricardo. A modernidade insustentável. Petrópolis: Vozes/UFSC, 1999 ----- \& VIOLA , Eduardo. Mudanças na direção de uma globalização multidimensional complexa. Cadernos de Pesquisa Interdisciplinar em Ciências Humanas. DICH/UFSC - n.40, Novembro de 2002.
}

Trata-se de experiências recentes e, como tal, os desafios são inúmeros, sobretudo no campo prático. Destacam-se direitos de acesso à informação, à participação pública na tomada de decisões e o acesso à justiça em matéria ambiental - cidadania socioambiental. Neste particular tem evoluído o papel da sociedade civil organizada.

As implicações e desafios descritos requerem uma postura interdisciplinar ${ }^{25}$ envolvendo temas relacionados à economia (Desenvolvimento Econômico Sustentável) e Gestão Pública (Políticas públicas; novos modelos de gestão: democráticos e participativos) e cultural (com o surgimento de novos bens ambientais, como o caso dos chamados conhecimentos de populações tradicionais).

Estes novos conceitos e desafios têm sido pano de fundo para a construção das políticas públicas ambientais em suas diversas áreas, em que destaca-se para o presente estudo a gestão integrada dos resíduos sólidos, que é um dos mais importantes temas, pois é fonte de inúmeros problemas socioambientais, em níveis local, regional e global.

\section{O desenvolvimento industrial e a emergência do desenvolvimento sustentável}

Com o crescimento das indústrias durante a Revolução Industrial iniciada nos princípios do séc. XVIII e expandida até o séc. XIX, houve um profundo impacto nos processos produtivos em nível econômico e social e ocorreu uma mudança nos padrões de consumo. ${ }^{26} \mathrm{~A}$ partir da década de 70 começa a tornar-se visível a desvantagem da industrialização, notando-se o empobrecimento da biodiversidade, poluição e alterações climáticas, a explosão dos grandes centros urbanos, a escassez de recursos naturais e a incapacidade do ecossistema planetário para reciclar resíduos sólidos. O primeiro passo para a emergência de uma consciência ambiental foi com o tema "Ecodesenvolvimento", no qual a partir dos movimentos ecológicos, como o Greenpeace, os Estados foram sensibilizados a agir contra as catástrofes naturais que acontecem em grandes dimensões

\footnotetext{
${ }^{25}$ Cf. MORAND, Charles-Albert. Le droit néo-moderne des politiques publiques. Paris: Librairie Générale de Droit et de Jurisprudence, 1999

${ }^{26}$ RAUEN, André Tortato. Ciência, Tecnologia e Economia: Caracteristicas frente à primeira e segunda Revoluções Industriais. Revista Espaço Acadêmico, nº66, 2006.
} 
por todo o mundo. Com o surgimento do conceito de Desenvolvimento Sustentável foram definidos valores comuns em prol da sobrevivência no planeta, a necessidade de uma estratégia global que possa travar o rumo atual do desenvolvimento econômico para um futuro ecológico do planeta.

Historicamente, embora as questões ligadas ao Desenvolvimento Sustentável não sejam estranhas à humanidade, seus antecedentes mais recentes estão ligados ao Clube de Roma, o qual alertava sobre a inviabilidade do crescimento econômico contínuo. Assim, em 1971 foi publicado um informe com o título "Limites do Crescimento", que advertia sobre a necessidade do crescimento zero. Na sequência, em 1974, no México, foi realizado um encontro das Nações Unidas no qual se elaborou a Declaração de Cocoyoc, que fazia menção ao termo sustentabilida$d e$. Este termo passou a ser assumido definitivamente em 1980 com a publicação da Estratégia Mundial da Conservação da Natureza. Todavia, a concretização e a difusão em escala planetária do termo só ocorreu após a reunião da Comissão Mundial para o Meio Ambiente-CMMAD.

De acordo com Michael, o projeto de Desenvolvimento Sustentável ganhou mais destaque em 1987 com a elaboração do Relatório Brudtland, que definia o Desenvolvimento Sustentável como sendo "aquele desenvolvimento que visa satisfazer as necessidades das gerações presentes sem no entanto comprometer a sobrevivência das gerações futuras". ${ }^{27}$ Camargo entende que o Relatório Brudtland, também conhecido por "Our Common Future" - em português, "nosso futuro comum" fundamentou-se numa análise comparativa entre a situação do mundo no começo e no final do século $\mathrm{XX}$, declarando que no princípio do século $\mathrm{XX}$ o número de pessoas existentes e a tecnologia vigente não prejudicavam significativamente os sistemas de apoio à vida na Terra e que, ao findar aquele século, a situação havia mudado radicalmente. ${ }^{28}$

A preocupação com o Desenvolvimento Sustentável representa a possibilidade de garantir mudanças sociopolíticas que não comprometam os sistemas ecológicos e sociais que sustentam as co-

\footnotetext{
${ }^{27}$ MICHAEL, P. Mc. Development and Social Change. A Global Perspective, London, Pine Forge Press, 1996, p.218.

${ }^{28}$ CAMARgO, Ana L. B. Desenvolvimento Sustentável: Dimensões e Desafios. 2 Edição. Campinas, SP: Papirus, 2005, p.53.
}

munidades. Neste sentido, o relatório Brudtland traçou um rol de medidas para serem tomadas pelos Estados: a limitação do crescimento populacional; a garantia de recursos básicos (água, alimentos, energia); a preservação da biodiversidade e dos ecossistemas; a diminuição do consumo de energia e o desenvolvimento de tecnologias com uso de fontes energéticas renováveis; o aumento da produção industrial nos países não-industrializados com base em tecnologias ecologicamente adaptadas; controle da urbanização desordenada e integração entre campo e cidades menores; o atendimento das necessidades básicas (saúde, escola, moradia), a adoção da estratégia de Desenvolvimento Sustentável pelas organizações de desenvolvimento (órgãos e instituições internacionais de financiamento); a proteção dos ecossistemas supranacionais, como a Antártica, e oceanos pela comunidade internacional; banimento das guerras; introdução de um programa de desenvolvimento sustentável pela Organização das Nações Unidas (ONU).

O relatório propôs também que o conceito de desenvolvimento sustentável deve ser assimilado pelas lideranças de uma empresa como uma nova forma de produzir sem degradar o meio ambiente, estendendo essa cultura a todos os níveis da organização, para que seja formalizado um processo de identificação do impacto da produção da empresa no meio ambiente e resulte na execução de um projeto que alie produção e preservação ambiental, com uso de tecnologia adaptada a esse preceito ${ }^{29}$.

\section{Desenvolvimento humano e desenvolvimento susténtavel}

O conceito de Desenvolvimento Humano foi introduzido pelo Programa das Nações Unidas para o Desenvolvimento - PNUD, com o objetivo de combater a pobreza no mundo. O PNUD é uma instituição multilateral com representação em 166 nações em todo o mundo, as quais trabalham juntas em busca de soluções para desafios na área do Desenvolvimento e Sustentabilidade. O programa foi criado para servir de auxílio aos países, e colaborar com a construção e soluções para desafios como, redução da pobreza, recuperação de países

\footnotetext{
${ }^{29}$ Relatório Brudtland,1987.
} 
devastados, utilização sustentável da energia e do meio ambiente, promoção de governabilidade democrática, inclusão digital, luta contra doenças, principalmente a AIDS.

Junto com os governos, o PNUD busca promover os direitos humanos, para proporcionar condições de vida mais favoráveis. ${ }^{30} \mathrm{Com}$ o mesmo objetivo, foi introduzido o Índice de Desenvolvimento Humano - IDH, o qual procura viabilizar uma visualização dos graus de Desenvolvimento Humano das diferentes regiões do mundo, fazendo um contrapeso ao Produto Interno Bruto - PIB. O PNUD admite que o IDH privilegie somente o campo econômico do desenvolvimento, embora se apresente como uma forma alternativa de mensurar o Desenvolvimento Humano.

O PNUD ainda reconhece algumas fragilidades no conceito do IDH ao constatar que o mesmo não abrange todos os aspectos de desenvolvimento. Tal medição, todavia, é baseada em três critérios: saúde, educação e renda, sendo que os critérios possuem pesos e medidas iguais, ou seja, todos têm igual importância. ${ }^{31}$

O Desenvolvimento Humano procura deslocar os esforços para a esfera humana do desenvolvimento, para além das esferas econômica, política, social. Por isso ela carrega a ideia de expandir, por meio da promoção de políticas públicas, as escolhas e oportunidades de cada pessoa. Em outros termos, o PNUD procura dar centralidade ao ser humano tendo como propósito seu desenvolvimento e não a acumulação de riquezas. Tal perspectiva é contrária ao ideal do desenvolvimento praticado após a II Guerra Mundial, que colocava o progresso econômico como principal objetivo dos modelos de desenvolvimento, sendo que as desigualdades sociais, as assimetrias mundiais e as catástrofes ambientais fizeram emergir a necessidade de construir novos modelos de desenvolvimento, mais justos tanto para o ser humano como para o ambiente.

Com o surgimento do debate sobre o Desenvolvimento Sustentável, abre-se espaço para se equilibrar as principais dimensões dos modelos de desenvolvimento, mormente, o social, o econômico e o

\footnotetext{
${ }^{30}$ Relatório de Desenvolvimento Humano, 2003, p.13.

31 ARBIX, Glauco; ZILBOVICIUS, M. \& ABRAMOVAY, Ricardo (org.), Razões e Ficções do Desenvolvimento. São Paulo, Editora da Unesp/Edusp, 2001, p.64.
}

ambiental de forma a assegurar a sobrevivência das gerações atuais e das futuras, e o Desenvolvimento Humano como uma questão fundamental para os modelos de desenvolvimento das sociedades, que se pretendem sustentáveis.

Desde a década 1960, as Nações Unidas tomaram consciência das assimetrias econômicas do mundo. Diante dessa situação, durante os anos 1990 foram promovidas conferências e encontros para a realização de debates das transformações que o planeta terra vinha enfrentando e iria enfrentar. $\mathrm{O}$ processo de industrialização originou fatores desestabilizadores das identidades em vários âmbitos. $\mathrm{O}$ mundo de hoje encontra-se dividido em um mundo desenvolvido, subdesenvolvido e pobre. ${ }^{32}$ Ambrósio considera que o Desenvolvimento Humano dependerá de condições de sustentabilidade do processo de desenvolvimento, isto é, dependerá de condições de responsabilidades cívicas de cada indivíduo.

O Desenvolvimento Humano tem a ver com pessoas, com a expansão de suas opções para viverem vidas plenas e criativas com liberdade e dignidade. Crescimento econômico, maior comércio, investimento e progresso tecnológico. O processo de desenvolvimento das sociedades, segundo o relatório do Desenvolvimento Humano, deve ter como diretriz a formação de sistemas democráticos que permitam a participação de todas as pessoas, de modo a que se sintam parte integrante e que contribuam para a sociedade em que vivem. ${ }^{33}$

GRIFFIM \& MCKINLEY são unânimes em considerar que uma abordagem baseada no Desenvolvimento Humano tem várias vantagens: primeiro, porque contribui diretamente para o bem-estar das pessoas; segundo porque é construído tendo por base a igualdade de oportunidades; terceiro, porque ajuda a criar uma distribuição mais igual dos benefícios do desenvolvimento; em quarto lugar, porque permite explorar os vários tipos de benefícios de investimento nas pessoas, e finalmente a vantagem de complementar o capital físico com o capital humano. ${ }^{34} \mathrm{~A}$ liberdade individual é a base e o meio mais eficaz

\footnotetext{
${ }^{32}$ MURTEIRA, Mário. A Emergencia de Uma Nova Ordem Mundial. Lisboa, Difusão cultural, 1995, p.95.

${ }^{33}$ AMBRÓSIO, Teresa. A Complexidade da Adaptação dos Processos de Formação e Desenvolvimento Humano. In: Formação e Desenvolvimento Humano: Inteligibilidade das suas Relações Complexas, Lisboa, 2003. 34 GRIFFIM, Keith \& MCKINLEY, Terry. Implementing a human development strategy, London, McMilan Press.1994, p.6.
} 
para a sustentabilidade da vida econômica e para a pobreza e insegurança.

A liberdade é tida como sinônimo de desenvolvimento, e o desenvolvimento visto enquanto liberdade. Existe um movimento recíproco entre ambos. Deste modo, a ação livre e sustentada surge como motor essencial do desenvolvimento. Amartya Sen conclui afirmando que o desenvolvimento precisa se referir à promoção da vida que construímos e às liberdades que usufruímos ${ }^{35}$.

\section{Pobreza e (in)justiça ambiental: o caso summers}

Em 1991, nas vésperas da realização da Conferência das Nações Unidas Sobre o Meio Ambiente e Desenvolvimento (ECO-92), o economista chefe do Banco Mundial Lawrence Summers escreveu um memorando que circulou nos Gabinetes do Banco Mundial e por causa de seu teor se espalhou pelo mundo inteiro. Fazendo uma tradução ipsis verbis, esse documento dizia o seguinte: "Cá entre nós, o Banco Mundial não deveria encorajar uma maior migração das indústrias mais poluentes para os LDC - Less Developed Countries, ou países menos desenvolvidos?". Lawrence acreditava que esta transferência de poluição para os países pobres e subdesenvolvidos fazia sentido econômico e tinha o que ele chamou de "lógica impecável", devendo ser enfrentada de frente. Summers fundamentava sua posição em três argumentos:

1. Pela lógica econômica as mortes e doenças provocadas pela poluição são mais baratas em países pobres, já que praticam salários mais baixos. Segundo ele, é óbvio que a preocupação com um agente nocivo que provoca uma probabilidade de câncer de próstata por milhão de pessoas será muito maior num país onde as pessoas vivem e consomem o suficiente para ter câncer de próstata do que noutro onde a mortalidade de crianças com menos de cinco anos é de muito maior.

2. Esses países normalmente são ainda pouco poluídos - ou em suas palavras: "sempre pensei que os países da África são extremamente subpoluídos, a qualidade de seu ar provavelmente

\footnotetext{
${ }^{35}$ SEN, Amartya. Desenvolvimento como Libedade. São Paulo: Scwarcs, 1999, p.31.
}

é vasta e a poluição ineficientemente baixa se comparada a Los Angeles ou Cidade do México".

3. É possível que, em função da pobreza, esses "miseráveis" não possam se preocupar com problemas ambientais, ou seja, o meio ambiente seria uma questão apenas estética, típica dos "bem de vida".

Como se pode ver, tratou-se claramente de uma ação de injustiça ambiental, no qual há uma lógica perversa de um sistema de produção, ocupação de solo, destruição de ecossistemas, alocação espacial de processos poluentes, que penalisa as condições de saúde de populações que moram em locais pobres, desfavorecidos e excluídos dos grandes projetos de desenvolvimento.

O conceito de injustiça ambiental define as situações em que a carga dos danos ambientais do desenvolvimento se concentra geralmente onde vivem populações mais vulneráveis e hiposuficientes. O termo injustiça ambiental é considerado como o paradoxo da justiça ambiental, ou seja, a necessidade de se trabalhar a questão do ambiente não apenas em termos de preservação, mas também de distribuição e justiça. Martinez compartilha a ideia de que a justiça ambiental representa o marco conceitual necessário para aproximar em um mesmo palco as lutas populares pelos direitos humanos, pela qualidade coletiva de vida e pela sustentabilidade ambiental. ${ }^{36}$ Trata-se de uma justiça socioambiental, que intregra as dimensões ambiental, social e ética da sustentabilidade e do desenvolvimento, frequentemente dissociados nos discursos e na prática. Porto-Gonçalves diz que, com o advento do ambientalismo nos anos 1960, cresceu a consciência de que há um risco global que se sobrepõe aos riscos locais, regionais e nacionais. ${ }^{37}$ De qualquer das formas, foram tantas as críticas ao Memorando Summers que, parecendo que não, acabou por contribuir na diminuição da fragmentação e do isolamento de vários grupos sociais, desfavorecidos e vulnerabilizados em função de suas situações econômicas. A justiça ambiental, mais do que uma expressão de âmbito jurídico, é um campo

\footnotetext{
${ }^{36}$ MARTINEZ, Paulo Henriques. História Ambiental no Brasil: pesquisa e ensino. São Paulo: Cortez, 2006.

${ }^{37}$ PORTO-GONÇALVES, Carlos Walter. A Globalização da Natureza e a Natureza da Globalização. Rio de Janeiro: Civilização Brasileira, 2006.
} 
de reflexão e mobilização de lutas de diversos estratos da sociedade afetada por riscos ambientais, já que as dificuldades que esses estratos enfrentam na compreensão do mundo atual contribuem imensamente para a reprodução desse quadro predominante de imobilismo e apatia, remata Martinez. ${ }^{38}$

\section{Pobreza e degradação ambiental}

A pobreza é vista como uma questão de privação, afetando o bem-estar das pessoas, sendo que essas privações de que sofrem os indivíduos em condição de pobreza são variadas e podem ser analisadas sob diferentes pontos de vista. O significado do que é pobreza assim como a forma de sua medição e avaliação são aspectos que dividem a opinião de grandes teóricos. Ravallion, por exemplo, considera que a pobreza constitui-se no fato de que, numa determinada sociedade, as pessoas não sejam capazes de atingir o nível material e de bem-estar assumido como o mínimo razoável nessa sociedade. Defende assim um estudo da pobreza a partir da renda, que considera uma boa medida de avaliação de oportunidades de consumo. ${ }^{39}$

A concepção da pobreza baseada no aspecto material é também vista por grande parte das organizações internacionais; tal é o entendimento da $\mathrm{ACEP}^{40}$, que considera pobre:

todo aquele que vive numa situação de privação permanente da satisfação das suas necessidades básicas tais como saúde, segurança alimentar, habitação, saneamento básico, água potável e outras, e ainda, de acesso á educação, á informação, á participação social e a um rendimento que confere a si e ao seu agregado familiar um modo de vida durável.

O estudo da pobreza a partir da renda levanta, contudo, um debate teórico. Para o PNUD, a pobreza é vista como uma negação de escolhas e de oportunidades para uma vida mais aceitável. No Relatório do Desenvolvimento Humano de 1997, o PNUD considera que a pobreza tem muitas facetas e que é mais do que uma questão de baixa renda, pois reflete

\footnotetext{
${ }^{38}$ MARTINEZ, Paulo Henriques. História Ambiental no Brasil: pesquisa e ensino. São Paulo: Cortez, 2006, p.15.

${ }^{39}$ RAVALLION, Martin. Pobreza versus crescimento, Rio de Janeiro: Valor Econômico. 2001.

${ }^{40}$ ACEP - Associativismo para a luta contra a pobreza e promoção do bemestar rural. Coleção Cooperação, Vol 1, Lisboa. 2000, p.38.
}

um problema de educação e saúde escassos, privação de conhecimento e de comunicação, falta de condições para exercer os direitos humanos e políticos, ausência de dignidade, confiança e respeito próprio. Professor emérito do Instituto Internacional de Estudos Sociais (ISS) da Erasmus University Rottendam, Marc Wuryts sugere dicotomias conceituais da pobreza, nomeadamente, a primeira em que a pobreza é vista como uma insuficiência de recursos ou como produto de desigualdades sociais e a segunda em que a pobreza é um estado em si ou comum processo. A pobreza como insuficiência de recursos significa analisar a pobreza enquanto problema de insuficiências que caracteriza os indivíduos de baixa renda e como uma condição específica de vida num dado momento. Finalmente, como um processo, significa centrar-se nos processos de empobrecimentos existentes numa sociedade.

Um estudo realizado por Cavendish sobre a relação entre a pobreza rural e degradação ambiental, o autor identificou nos países pobres uma contribuição dos recursos naturais na composição da renda dos agricultores, bem como a importância que esses recursos têm em várias atividades exercidas pelos pobres. Os resultados do estudo mostraram que, se por um lado os pobres são mais dependentes dos recursos naturais do que os ricos, por outro, os ricos exploram quantidades muitos superiores às quantidades utilizadas pelos agricultores pobres, pois a procura dos recursos naturais varia de acordo com a renda de cada pessoa, família e Estado. O estudo conclui que a crescente procura dos recursos naturais e a má utilização desses recursos causam degradação ambiental, e que a pobreza é a maior causa da degradação ambiental. ${ }^{41}$

As multidimensões da condição de pobreza devem ser levadas em consideração ao analisar-se a relação entre essa condição e a degradação ambiental, já que a pobreza é um conceito complexo e não pode ser precisamente mensurada e entendida por índices estatísticos como linha de pobreza, por exemplo. Este é o entendimento da IUCN. ${ }^{42}$

A vida econômica de muitos pobres rurais parece ser diretamente dependente da exploração de terras, as quais são altamente vulneráveis à

\footnotetext{
${ }^{41}$ CAVENDISH, WILIAM. Empirical Regularities in the Povertyenvironment Relationship of African Rural households, 1999.

${ }^{42}$ IUCN- International Union for Consenvation of Nature, 2003, p.8
} 
degradação. Barbier diz que a pobreza extrema desses agricultores influencia suas habilidades e disposições de controlar a degradação das terras, e, para o autor, o pobre transforma a terra em subsistência, fazendo que a pobreza rural tenha um papel significativo na degradação do meio ambiente. ${ }^{43}$

\section{Considerações finais}

O meio ambiente ou ecossistema em que vivemos está em constante transformação devido à ação direta do ser humano sobre ele, tanto pelo desenvolvimento como pela pobreza. A intervenção humana sobre o ambiente trouxe e continua a trazer consequências graves que se tornam evidentes em diferentes escalas, tornando-se paradoxo ao desenvolvimento sustentável. A intensidade desta intervenção humana sobre o ecossistema é tal que, muitas vezes, a destruição de recursos ultrapassa a capacidade de recuperação dos mesmos, sendo que a utilização crescente dos recursos não renováveis é um dos exemplos mais flagrantes da atualidade.

O modelo de desenvolvimento industrial baseado no consumo excessivo de recursos naturais levou a um desastre energético acima dos valores suportáveis pelo planeta, causando consequentemente um enorme cenário de poluição do ar e da água, ameaças para a natureza, destruição da camada de ozono, aquecimento global.

Já a pobreza é vista como uma questão de privação, afetando o bem-estar das pessoas, há relação entre a pobreza rural e degradação ambiental; o autor identificou nos países pobres uma contribuição dos recursos naturais na composição da renda dos agricultores, bem como a importância que esses recursos têm em várias atividades exercidas pelos pobres.

Nesta mesma acepção, parece evidente que o sistema de desenvolvimento adotado pelos países acarreta pobreza e desigualdade social e, por consequência, de injustiça social, sendo estas sociedades desprovidas de capacidade material, intelectual, alimentar, dentre outros, os principais focos de instalação de sistemas que causam ainda mais desigualdades, doenças etc.

\footnotetext{
${ }^{43}$ BARBIER, E. Land Degradation and Rural Povert in África: Examining the Evidence. UNU/INRA annual Lectures, 1998.
}

Se por um lado os pobres são mais dependentes dos recursos naturais do que os ricos, por outro, os ricos exploram quantidades muitos superiores as quantidades utilizadas pelos agricultores pobres, pois a procura dos recursos naturais varia de acordo com a renda de cada pessoa, família e Estado. A crescente procura dos recursos naturais e a má utilização desses recursos causam degradação ambiental.

Como o objetivo principal era erradicar a pobreza no mundo, recuperar os países devastados e criar mecanismos de utilização sustentável da energia e do meio ambiente, o Programa das Nações Unidas para o Desenvolvimento (PNUD) introduziu o conceito de Desenvolvimento Humano. Com o mesmo objetivo, foi introduzido o Índice de Desenvolvimento Humano - IDH, que procura viabilizar uma visualização dos graus de Desenvolvimento Humano das diferentes regiões do mundo, fazendo um contrapeso ao Produto Interno Bruto - PIB.

\section{Referências Bibliográficas}

ACEP - Associativismo para a luta contra a pobreza e promoção do bem-estar rural. Coleção Cooperação, Vol. 1, Lisboa. 2000.

AMBRÓSIO, T. A Complexidade da Adaptação dos Processos de Formação e Desenvolvimento Humano. In: Formação e Desenvolvimento Humano: Inteligibilidade das suas Relações Complexas, Lisboa, 2003.

ARBIX, G.; ZILBOVICIUS, M. \& ABRAMOVAY, R. (org.), Razões e Ficções do Desenvolvimento. São Paulo, Editora da Unesp/Edusp, 2001.

BALDO, I. Junior. CUSTÓDIO, A. V. Desenvolvimento Urbano: Um discurso sobre a organização socioambiental e habitacional so a panorâmica da igualdade e da justiça em John Rawls. In: CUSTÓDIO; A.V. BALDO, I. Junior (orgs). Meio Ambiente Constituição \& Políticas Públicas. Curitiba: Multideia, 2011

BARBIER, E. Land Degradation and Rural Povert in África: Examining the Evidence. UNU/INRA annual Lectures, 1998.

BREITENBACH, C. e REIS, J. R. (In)suficiência dos preceitos constitucionais ambientais na pós-modernidade frente ao paradigma econômico. In: CUSTÓDIO; A.V., BALDO, I. Junior (orgs). Meio Ambiente Constituição \& Políticas Públicas. Curitiba: Multideia, 2011.

BROWN , L. R. Eco-économie - une autre croissance est possible, écologique et durable. Paris : Seuil, 2003. 
CAMARGO, A. L. B. Desenvolvimento Sustentável: Dimensões e Desafios. 2a edição. Campinas, São Paulo: Papirus, 2005.

CAVENDISH, W. Empirical Regularities in the Poverty: environment Relationship of African Rural households, WPS 99-21, set. 1999.

CHIRAS, D.D. New Visions of Life: Evolution of a Living Planet. I: Environmental Science: Action for a Sustainable Future. $3^{\circ}$ Edition. Benjamim Cummings Publishing. Cap: 02. Disponível em: <http://xucurus. blogspot.com/2010/08/meio-ambiente-e-producao-de-lixo. html>. Acesso em 16.11.2012.

CRUZ, P. M., BODNAR, Z., STAFFEN, M. R. Transnacionalización, Sostenibilidad y el nuevo paradigma del Derecho in Siglo XXI. Revista Opinión Jurídica Universidad de Medellín, 2011.

CRUZ, P. M., BODNAR, Z.. O novo paradigma do Direito na Pós Modernidade. Revista de Estudos Constitucionais, Hermenêutica e Teoria do Direito (RECHTD). UNISINOS 3(1): 75-83 janeiro-junho 2011.

FERREIRA, J. M. de B. e FERREIRA, C. A.. A sociedade da informação e o desafio da sucata eletrônica. Revista de Ciências Exatas e Tecnologia. Faculdade Anhanguera, São Paulo. Vol. III, nº. 3, ano 2008.

FERRER, G. R. La construcción del Derecho Ambiental. Revista Arazandi de Derecho Ambiental. Pamplona. España. n. 1, 2002.

FURTADO, F. A. M.. Concepções éticas da proteção ambiental. Brasília. Instituto Brasiliense de Direito Público, 2003.

GIDDENS, A. As consequências da modernidade. Tradução de Raul Fiker. Sao Paulo: Unesp. 1991.

GORCZEVSKI, C. e MORAIS, D. E. A crise da percepção ambiental e os mecanismos constitucionais que permitem o exercício da cidadania na proteção do meio ambiente: Uma análise a partir da obra A Teia da Vida, de Fritjof Capra e A Teoria da Constituição como Ciência da Cultura, de Peter Haberle. CUSTÓDIO; A.V., BALDO, I. Junior (orgs). Meio Ambiente Constituição \& Políticas Públicas. Curitiba: Multideia, 2011.

GRIFFIM, K. \& MCKINLEY, T. Implementing a human development strategy, London, McMilan Press.1994.

HOBSBAWN, E. Globalização, democracia e terrorismo. Trad. José Viegas. São Paulo: Companhia das Letras, 2007.

HOBSBAWN, E. Globalização, Democracia e Terrorismo. Trad. José Viegas. São Paulo: Companhia das Letras, 2007, p.9.

IUCN- International Union for Consenvation of Nature, 2003.
LEIS, H. R. A modernidade insustentável. Petrópolis: Vozes/UFSC, 1999 ----- \& VIOLA, E. Mudanças na direção de uma globalização multidimensional complexa. Cadernos de Pesquisa Interdisciplinar em Ciências Humanas. DICH/ UFSC N.40, Novembro de 2002

MARTINEZ, P. H. História Ambiental no Brasil: pesquisa e ensino. São Paulo: Cortez, 2006.

MICHAEL, P. Mc. Development and Social Change. A Global Perspective, London, Pine Forge Press, 1996.

MORAND, C-A. Le droit néo-moderne des politiques publiques. Paris: Librairie Générale de Droit et de Jurisprudence, 1999.

MURTEIRA, M. A Emergencia de Uma Nova Ordem Mundial. Lisboa, Difusão cultural, 1995.

PEREIRA, J.R.G. Apontamentos sobre a aplicação das normas de direito fundamental nas Relações Jurídicas entre Particulares. In: BARROSO, L.R. A nova Interpretação constitucional: Ponderação, Direitos fundamentais e Relações Privadas. Rio de Janeiro: Renovar, 2003.

PORTO-GONÇALVES, C.W. A Globalização da Natureza e a Natureza da Globalização. Rio de Janeiro: Civilização Brasileira, 2006.

RAUEN, A.T. Ciência, Tecnologia e Economia: Caracteristicas frente à primeira e segunda Revoluções Industriais. Revista Espaço Acadêmico - nº6, 2006.

RAVALliON, M. Pobreza versus crescimento, Rio de Janeiro: Valor Econômico. 2001.

Relatório Brudtland,1987.

Relatório de Desenvolvimento Humano, 2003.

SEN, A. Desenvolvimento como Libedade. São Paulo: Scwarcs, 1999.

SOARES, R. A. de A. Proteção ambiental e desenvolvimento econômico. $1^{\text {a }}$ Ed., Curitiba: Juruá, 2005.

Recebido em 16 de agosto de 2013

Aceito em 10 de outubro de 2013 